\title{
Sudden death in a patient with amyloidosis of the cardiac conduction system
}

\author{
D C ALLEN, C C DOHERTY \\ From the Histopathology Laboratory and Department of Nephrology, Belfast City Hospital, Belfast, Northern Ireland
}

SUMMARY A 54 year old man had generalised systemic amyloidosis secondary to bilateral basal bronchiectasis of the lungs. He died after an unexpected asystolic cardiac arrest. Necropsy showed extensive amyloid deposition in the cardiac conduction system.

Cardiac amyloidosis is a well established but uncommon cause of haemodynamic and electrocardiographic abnormalities. ${ }^{1-11}$ Several workers have incriminated to varying degrees the presence of amyloid deposits within the cardiac conduction system as the underlying pathophysiology..$^{5-11}$ We report a case of systemic amyloidosis occurring in a 54 year old man secondary to bilateral basal bronchiectasis, who died after a sudden asystolic cardiac arrest due to direct amyloid deposition in his conduction system. An abnormal electrocardiogram was recorded eight months before death.

\section{Case report}

A 54 year old man was admitted to Belfast City Hospital for evaluation of chronic renal failure. He had a history of bronchiectasis, and nephrogenic diabetes insipidus had been diagnosed two years previously after investigations for polyuria. The cause of his renal failure was considered to be renal amyloidosis since gastric and rectal biopsy specimens stained positively with congo red. Since his creatinine clearance was 11 $\mathrm{ml} / \mathrm{min}$ an arteriovenous fistula was created in anticipation of the need for haemodialysis. A 12 lead electrocardiogram recorded at this time showed a sinus rhythm of 65 beats/min with first degree heart block (PR interval $0.28 \mathrm{~s} ;$ QRS interval $0.11 \mathrm{~s}$ ) and incomplete left bundle branch block (Fig. 1). An unspecific ST/T wave abnormality was also present. $\mathrm{He}$ was readmitted to hospital eight months later complaining of breathlessness and neck swelling.

Requests for reprints to Dr Derek C Allen, Histopathology Laboratory, The Laboratories, Belfast City Hospital, Belfast BT9 7AD, Northern Ireland.
Examination showed sinus rhythm, no signs of heart failure, and a diffuse goitre. Renal function was little changed with a creatinine clearance of $10 \mathrm{ml} / \mathrm{min}$, a serum urea concentration of $16.9 \mathrm{mmol} / \mathrm{l}(1.0 \mathrm{~g} / \mathrm{l})$, and a serum potassium concentration of $3.7 \mathrm{mmol}(\mathrm{mEq}) / 1$. He was treated for exacerbation of bronchiectasis, but despite initial improvement sudden cardiac arrest occurred 24 hours later. His electrocardiograms showed asystole, and resuscitation was unsuccessful.

\section{NECROPSY FINDINGS}

Necropsy showed enlarged emphysematous lungs with pronounced bronchiectatic changes in both bases. The peripheral airways were dilated and congested, and the overlying pleural cavities contained fibrous adhesions. The other organs were affected to varying degrees by amyloid infiltration. The kidneys and parathyroid glands showed an obvious waxy pallor, and a pronounced amyloid goitre $(110 \mathrm{~g})$ was evident. Histological examination showed involvement of the liver, spleen, skin, other endocrine glands, and the gastrointestinal tract. Lung deposition was minimal.

The total heart weight was $580 \mathrm{~g}$, and there was moderate biventricular dilatation and hypertrophy. The aorta and coronary arteries contained only a minimal amount of atheroma, and wide lumen patency was maintained at all points. The pericardium was translucent, and the valves were not thickened. Histological examination did not show any recent or long standing ischaemic myocardial damage. The ventricular interstitium and its vessels contained small amounts of congo positive amyloid. The subendocardial aspects of both atria contained focal amyloid deposits, but the cardiac valves, pericardium, and epicardial vessels and nerves were not affected. 

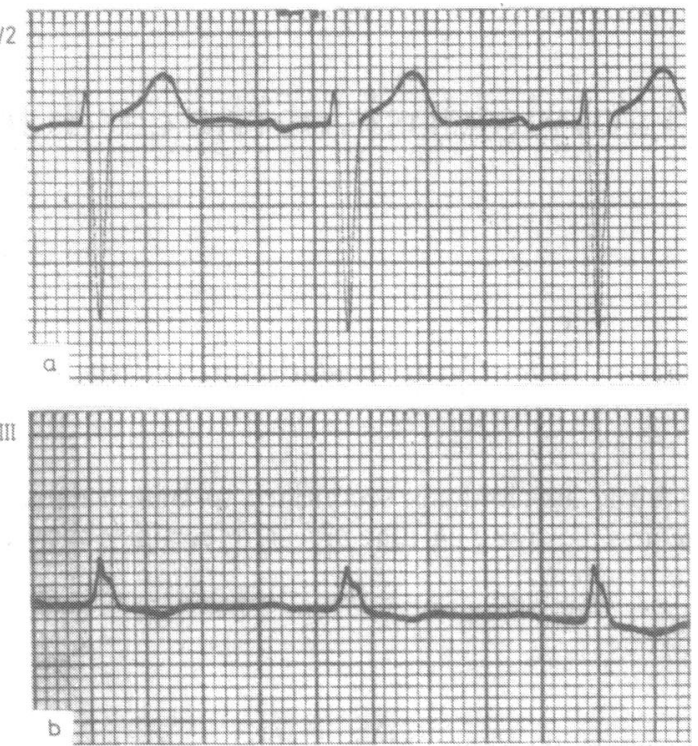

Fig. 1 Twelve lead electrocardiogram showing $(a)$ a prolonged $P R$ interval $(0 \cdot 28 \mathrm{~s})$ and $(b)$ incomplete bundle branch block.

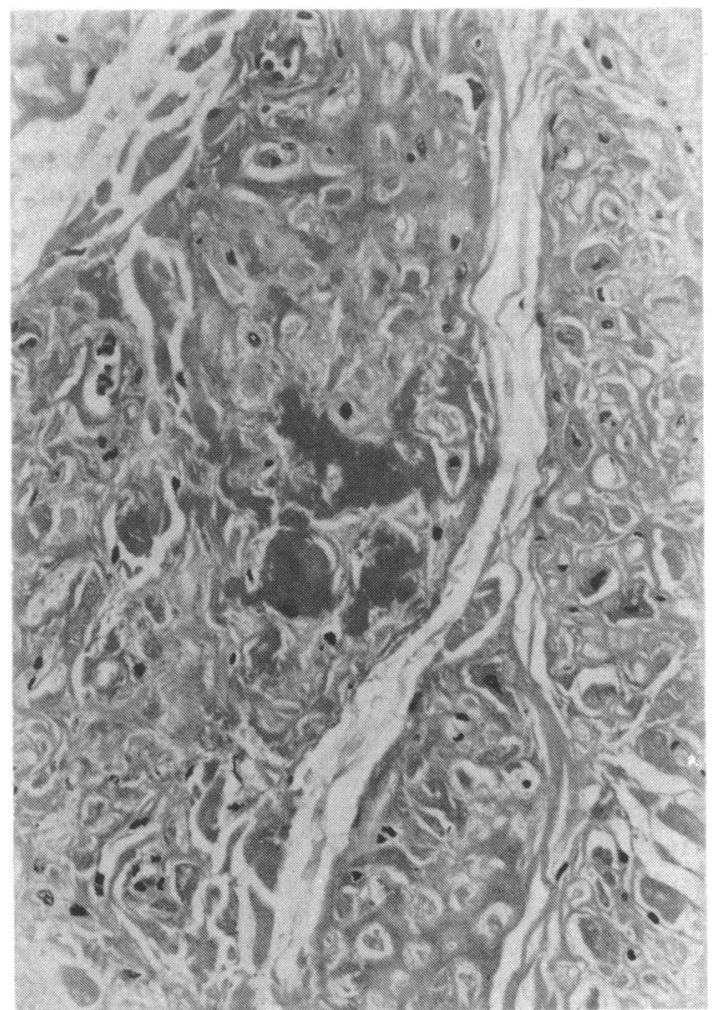

Fig. 2 Histological section showing the sinoatrial node containing extensive amorphous amyloid deposits both surrounding and replacing conducting myofibrils. (Haematoxylin and eosin $\times 300$ original magnification.)
The sinoatrial node contained extensive amyloid, and the branches of its supplying artery were diffusely thickened (Fig. 2). The main nodal artery was not involved. Amyloid had also been deposited in the atrioventricular node, the His bundle as it penetrated the central fibrous body (Fig. 3), and the left main bundle branch. The myofibrils were intimately mixed with homogeneous eosinophilic amyloid. The absence of appreciable nodal and conducting element fibrosis was confirmed using a sodium alcian blue stain. It was interesting to note that amyloid deposition was notably heavier in the conduction system than in the myocardium.

\section{Discussion}

Dissection of the main components of the human cardiac conduction system is well documented. ${ }^{12}$ The sinoatrial node lies at the crest of the right atrial appendage where it joins the superior vena cava. The atrioventricular node lies anterior to the coronary sinus beneath the right atrial endocardium, and the main His bundle runs forward and down through the central fibrous body below the membranous septum. Serial blocks and examination at multiple levels are required. The paraffin processed tissue sections in this patient were stained orange-red with alkaline congo red, and these amyloid deposits showed an apple green birefringence under polarised light. Presence of amyloid was confirmed by staining with sodium alcian blue, and with thioflavine $T$ viewed for fluorescence under ultraviolet light (Fig. 3b). The sections were also sensitive to potassium permanganate decolorisation, a feature considered by some to be histological confirmation of secondary amyloid. ${ }^{13}$

Cardiac amyloidosis is classically thought of as an infiltrative cardiomyopathy with subsequent cardiac failure which may be refractory to conventional treatment. It may mimic the clinical picture of constrictive pericarditis and the electrocardiographic changes of healed infarction. ${ }^{1}{ }^{3}$ Unspecific electrocardiographic abnormalities such as low voltage and axis deviation have been noted. James ${ }^{5}$ asserted that the "disturbance of cardiac function and conduction are in a significant amount due to the amyloid infiltration directly" (that is, of the conduction system). He found heavy sinoatrial node deposits and atrial fibrillation in two of his five cases. Others have since reinforced his comments, ${ }^{9}{ }^{10}$ but sinus rhythm has also been reported in the presence of severe conduction system infiltration. ${ }^{6} 8$ Prolongation of the PR interval and bundle branch block are well documented in amyloid heart disease. Bharati et al reported a case of recurrent ventricular fibrillation and extensive cardiac conduction system deposition of amyloid. ${ }^{10}$ In 1960 sudden death occurred in two cases 

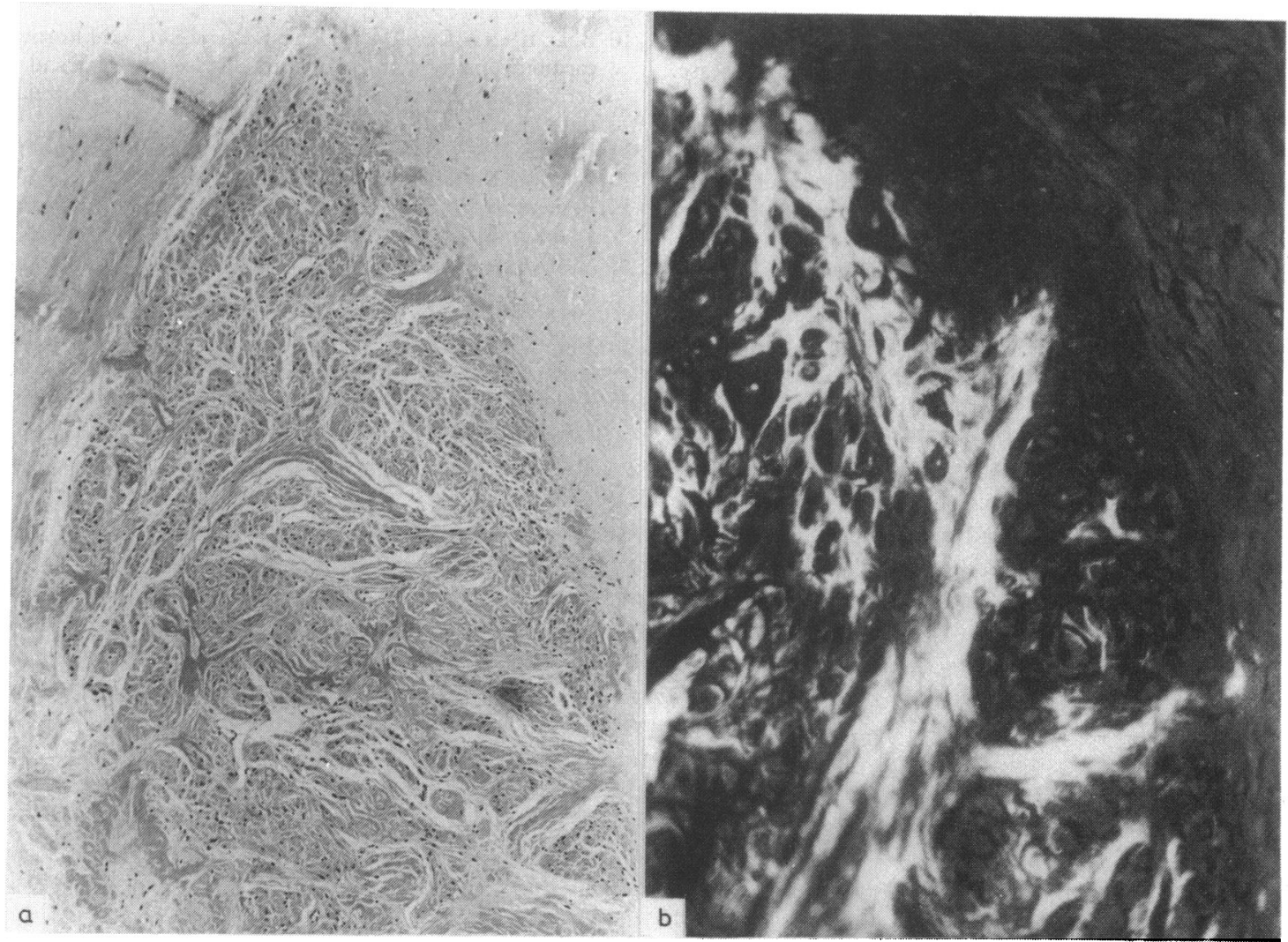

Fig. 3 Histological section showing the main His bundle penetrating the central fibrous body and extensive amyloid deposition intimately mixed with conducting elements (haematoxylin and eosin $\times 125$ original magnification); and (b) a higher power view of the His bundle with the central fibrous body in the top right corner; abundant amyloid is confirmed (thioflavine $T$ viewed under ultraviolet light $\times 400$ original magnification).

of primary cardiac amyloidosis associated with atrioventricular node and His bundle infiltration. ${ }^{14}$ In a series by Wright and Calkins ${ }^{13} 30 \%$ of their patients with primary amyloidosis died suddenly, probably from arrhythmic cardiac involvement. This danger had been noted elsewhere but not substantiated by conduction system dissection in either case. ${ }^{15}$ Sudden death occurred in our patient in the absence of severe atheromatous disease or electrolyte abnormalities and in the presence of conduction system amyloid infiltrates.

Two main aetiological factors have been suggested for dysfunction in amyloid heart disease. The coronary or intramyocardial vessels may be thickened causing ischaemic lesions, 5 and the amyloid deposition may atrophy the parenchyma directly. The latter mechanism leads to a less compliant and contractile myocardium with haemodynamic disturbances. Our patient had amyloid throughout his conduction system, increasing the functional implications of the deposits. This was confirmed by an abnormal electrocardiogram showing first degree heart block and incomplete left bundle branch block.

This case therefore illustrates the potential hazard of sudden death from conduction system disease in patients with generalised systemic amyloidosis.

We thank Dr J D Biggart for his advice on the pathological specimens and $\mathrm{Dr} M \mathrm{E}$ Scott for reviewing the electrocardiogram. We also thank Mr John Orchin for his technical and photographic expertise.

\section{References}

1 Wessler S, Freedburg AS. Cardiac amyloidosis; electrocardiographic and pathologic observations. Arch Intern Med 1948; 82: 63-74.

2 Mulligan RM. Amyloidosis of the heart. Archives of Pathology 1958; 65: 615-30. 
3 Cassidy JT. Cardiac amyloidosis. Two cases with digitalis sensitivity. Ann Intern Med 1961; 55: 989-94.

4 Farrokh A, Walsh TJ, Massie E. Amyloid heart disease. Am f Cardiol 1964; 13: 750-6.

5 James TN. Pathology of the cardiac conduction system in amyloidosis. Ann Intern Med 1966; 65: 28-36.

6 Garcia R, Saeed SM. Amyloidosis. Cardiovascular manifestations in five illustrative cases. Arch Intern Med 1968; 121: 259-66.

7 Buja LM, Khoi NB, Roberts WC. Clinically significant cardiac amyloidosis. Clinicopathologic findings in 15 patients. Am f Cardiol 1970; 26: 394-405.

8 Ridolfi RL, Bulkley BH, Hutchins GM. The conduction system in cardiac amyloidosis. Clinical and pathologic features of 23 patients. Am $\mathcal{F}$ Med 1977; 62: 677-86.

9 Isokane N, Fukushima N, Miyazaki T, Dohi I. A case of sick sinus syndrome in primary systemic amyloidosis. $\mathcal{F}$
Electrocardiol 1978; 11: 191-6.

10 Bharati $\mathrm{S}$, Lev $\mathrm{M}$, Denes $\mathrm{P}$, et al. Infiltrative cardiomyopathy with conduction disease and ventricular arrhythmia: electrophysiologic and pathologic correlations. Am F Cardiol 1980; 45: 163-73.

11 Davies MJ. Pathology of conducting tissue of the heart. London: Butterworths, 1971: 105-6.

12 Pomerance A, Davies MJ. The pathology of the heart. London: Blackwell Scientific Publications, 1975: 26-31.

13 Wright JR, Calkins E. Clinical-pathologic differentiation of common amyloid syndromes. Medicine (Baltimore) $1981 ; 60$ : 429-48.

14 Lumb G, Shacklett RS. Human cardiac conduction tissue lesions. Am F Pathol 1960; 36: 411-29.

15 Kyle RA, Bayrd ED. Amyloidosis: review of 236 cases. Medicine (Baltimore) 1975; 54: 271-99.

\section{British Cardiac Society}

The Annual General Meeting for 1984 will take place in Leicester on 11 and 12 April 1984, and the closing date for receipt of abstracts was 3 January 1984.

The Autumn Meeting in 1984 will be held on 3 and 4 December 1984, and the closing date for receipt of abstracts will be 15 August 1984 . 